\title{
Prediction of the stress level and stress concentration in cellular beams with circular openings
}

\author{
A. I. Pritykin*, A.S. Lavrova** \\ *Kaliningrad State Technical University (KGTU), Sovetsky av. 1, 236022, Kaliningrad, Russia, \\ E-mail:prit_alex@mail.ru \\ *Immanuel Kant Baltic Federal University, A. Nevskogo str. 14, 236041, Kaliningrad, Russia \\ **Kaliningrad State Technical University (KGTU), Sovetsky av. 1, 236022, Kaliningrad, Russia, \\ E-mail: a.lavrova39@gmail.com
}

cross $^{\text {ref }}$ http://dx.doi.org/10.5755/j01.mech.23.4.15136

\section{Introduction}

Although stress concentration in vicinity of regularly located circular openings under axial tension is well researched [1], in this work the problem was investigated in aspect of transverse bending of cellular beam, when simultaneous action of shear force and bending moment take place and pure bending.

For today the main shapes of perforations are hexagonal and circular openings, which are produced on unwaste technology. Comparison of strength of such beams for choice of optimal design solution is possible in first turn with estimation of their stress state. In spite of numerous works dedicated to estimation of stress level in perforated beams as foreign [2-14], so and Russian [15, 16] authors, there is no analytical expression for evaluation of stresses in zones of concentration. In all works the analysis of stress state is performing on base of calculation by finite element method, sometimes accompanied with experiments. More often in them there are only numerical values and colored fields of stress distribution. To generalize such results or use them for predicting of stress level in designed beam is rather difficult.

In the work it was obtained the analytical expression for maximum equivalent stresses on Mises in beams

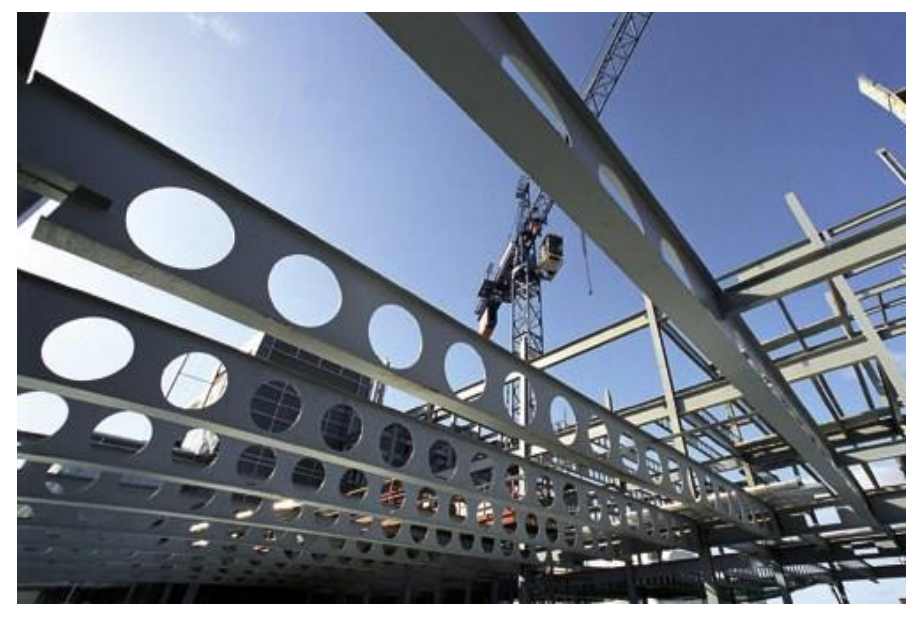

a with circular openings. These beams are distinguished with wide spectrum of sizes (Fig. 1), but in this work it was changed only one parameter of perforation - relative width of web-posts. The relative depth of openings was remained unchangeable and equal to $\xi=0.667$. It was also investigated influence of web thickness on the stress level.

Investigation of stress distribution in cellular beams with circular openings was made under two kinds of loading:

-under transverse bending when shear force at any section is constant and flexure moment is changing on lineal law;

- under pure bending, when shear force is absent. Stress concentration was evaluated under pure bending.

\section{Theoretical approach}

Before to come to estimation of the stress level it was solved task of determination of equivalent stresses in vicinity of opening under transverse bending. It was considered simply supported beam, performed from plate elements and loaded with concentrated force in mid-span. Such loading produce deformation of transverse bending under constant shear force.

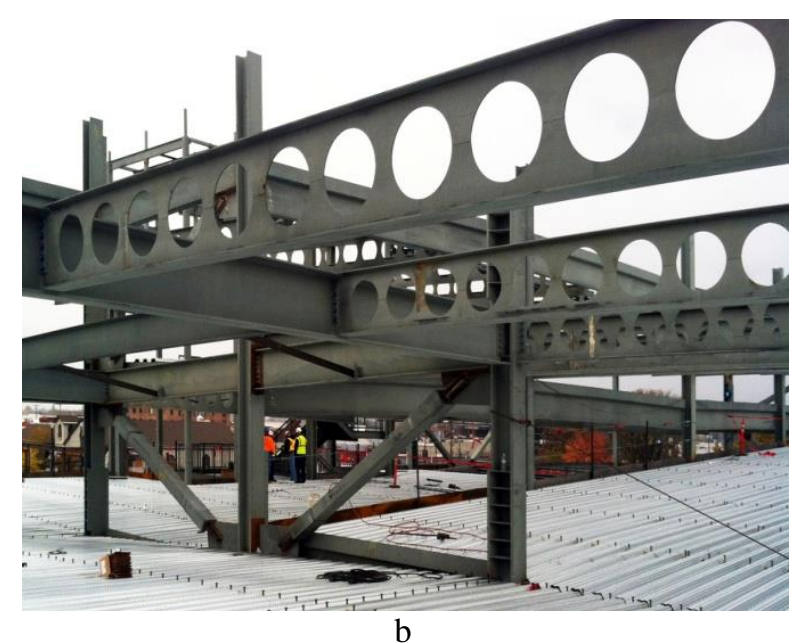

Fig. 1 Cellular beams with different width of web-posts: a) $c / d=0.5$; b) $c / d=0.25$

Web perforation is determining with three parameters: diameter of opening $d$, width of web-post $c$, representing by itself minimum distance between edges of two adjacent openings, and width of ended web-post $c_{0}$
(Fig. 2). For denomination of the beam dimensions in work it was used next abbreviated form of writing: $l-H-t_{w}-b_{f}-t_{f} c m-\beta-\xi$, which completely determine their geometry. Incoming magnitudes are interpreted 
as: $l$ is beam length, $H$ is full height of it, $t_{w}$ is thickness of web, $b_{f}$ is width of shelves, $t_{f}$ is thickness of shelves, $\beta=d / H$ is relative height of openings, $\xi=c / d$ is relative width of web-post. Dimensions of beam are indicated in centimeters.

Program of calculation included investigation of influence on value $\sigma_{\max }^{\text {eqv }}$ relative width of web-posts $\xi$ in range $0.15 \leq \xi \leq 0.5$ (Fig. 3) under relative height of openings $\beta=0.667$. Indicated diapason of width of web-posts embraces practically whole spectrum of perforation of such beams.

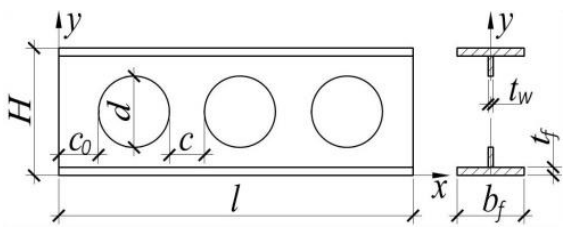

Fig. 2 Parameters of cellular beam

Derivation of relation for equivalent stresses is realized on analysis of calculation of cellular beams with FEM using program complex ANSYS.

Under transverse bending definite role in value of stress concentration factor (SCF) $\alpha_{\sigma}$ play as flexure moment $M$ so and shear force $V$. Flexure moment $M$ determine level of normal stresses $\sigma_{x}$, and force $V$ is connected with level of shear stresses $\tau_{x y}$ in cross section. Although technical theory of flexure consider plane stress state of solid web including only two stress components $\sigma_{x}$ and $\tau_{x y}$, in perforated beams in regions of openings the normal stresses $\sigma_{y}$ reach also significant value. Due to it in vicinity of the opening contour takes place complex stress state, integral parameter of which for next evaluation of SCF under joint action of $\sigma_{x}, \sigma_{y}$ and $\tau_{x y}$ can be equivalent stresses on Mises $\sigma_{\max }^{e q v}$. In common form it can be expressed via stress components as:

$$
\sigma_{\max }^{e q v}=\sqrt{\sigma_{x}^{2}-\sigma_{x} \sigma_{y}+\sigma_{y}^{2}+3 \tau_{x y}^{2}} .
$$

The value of stress concentration factor $\alpha_{\sigma}$ can be calculated on relation:

$$
\alpha_{\sigma}=\sigma_{\max }^{e q v} / \sigma_{\max }^{T T},
$$

where $\sigma_{\max }^{T T}$ is maximum stress in flange of beam with solid web, determined on technical theory of flexure as:

$$
\sigma_{\max }^{T T}=M_{x} / W
$$

where $M_{x}$ is flexure moment caused with external load in section $x$, where stresses $\sigma_{\max }^{\text {eqv }}$ are determining; $W$ is modulus of beam's cross section with solid web:

$$
W \approx b_{f} t_{f} H+H^{2} t_{w} / 6 .
$$

So far as under transverse flexure on value $\sigma_{\max }^{\text {eqv }}$ influent the shear force $V$ and bending moment $M$, magnitude $\sigma_{\max }^{\text {eqv }}$ can be represented as sum of two terms:

$$
\sigma_{\max }^{e q v}=\alpha_{V} \frac{V}{H t_{w}}+\alpha_{M} \frac{M}{W},
$$

where $\alpha_{V}$ and $\alpha_{M}$ are numerical coefficients, determined from FEM calculations.

Magnitude of flexure moment $M_{x}$ for $n$-th opening can be written as:

$$
M_{x}=V x=V(n-1) s,
$$

where $s$ is step of openings; $n$ is ordinal number of opening, in vicinity of which the equivalent stresses $\sigma_{\max }^{\text {eqv }}$ are determining.

In common case the step of openings can be determined as:

$$
s=d+c .
$$

Taking into account that $d=\beta H$, and $c=\xi d$ then from Eq. (7) it follows:

$$
s=(1+\xi) \beta H .
$$

Substitution of Eq. (4), Eq. (6) and Eq. (8) in Eq. (5) after simple transformation leads to relation

$$
\sigma_{\max }^{e q v}=\left(\alpha_{V}+\alpha_{M} \frac{(n-1)(1+\xi) \beta}{6 b_{f} t_{f} / H t_{w}+1}\right) \frac{V}{H t_{w}} .
$$

So for calculation $\sigma_{\max }^{e q v}$ it is need to determine numerical coefficients $\alpha_{V}$ and $\alpha_{M}$.

Initially it was considered simply supported cellular beam loaded with concentrated force $P$ in mid-span; in second case the beam was loaded with two equal forces $P$, applied at equal distances from supports, that produced deformation of pure flexure in the middle part of beam.

For getting reliable results by FEM in vicinity of openings it was adopted refined mesh of finite elements with sizes $\Delta_{F E}=2 \mathrm{~mm}$ and dimensions of FE in other part of beam were equal to $\Delta_{F E}=2 \mathrm{~mm}$. Such combination of dimensions assured high accuracy of solution with minimum waste of the calculation's time. For additional reducing the equations system NEQ it was taken in a view the symmetry of structure, which allow considering only half of beam. Once more approach of reducing dimensions of NEQ was application of mesh of FE not along the whole contour of opening but only on half of it where high stresses are expected. Beside of this, refined mesh was applied not at every hole but only near every fifth, so as number of openings along the beam was too big and reached 100-130. Indicated peculiarities allow reducing the number of equations till 150-300 thousands. 
Under transverse bending it was investigated influence of web thickness $t_{w}$ and relative width of webposts $\xi$ under constant relative height of openings $\beta=0.667$ on a level of equivalent stresses near openings.
Stress state of all beams was appreciated for simply supported beams under the same shear force $V=1 k N$, which is equal to reaction of support (Fig. 3).

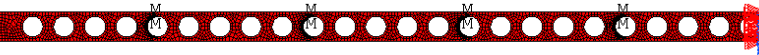

\section{0}

$\mathrm{b}$

Fig. 3 Calculated scheme of beam with: a) wide $\xi=0.5$ and b) narrow $\xi=0.15$ web-posts

\section{Numerical calculations}

Initially determination of influence of web-post width on $\sigma_{\max }^{e q v}$ was investigated on beams with dimensions $4000-40-0.3-10-0.3 \mathrm{~cm}-0.667-\xi$, and different values of $\xi$ in range $0.15 \leq \xi \leq 0.5$.
Results of calculation by FEM of three beams with values of $\xi=0.5 ; 0.25$ and 0.15 respectively are shown in Fig. 4, in which equivalent stresses on Mises $\sigma_{\max }^{\text {eqv }}$ were measured according to Eq. (1) in low parts of openings. To the right of each picture of beam in Fig. 4 the numbers of openings are indicated, where stresses were fixed.

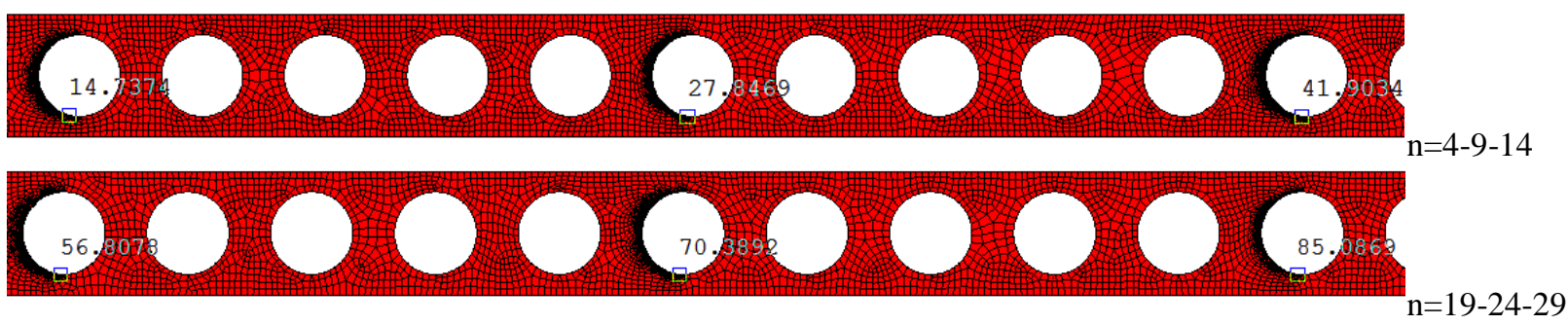

a

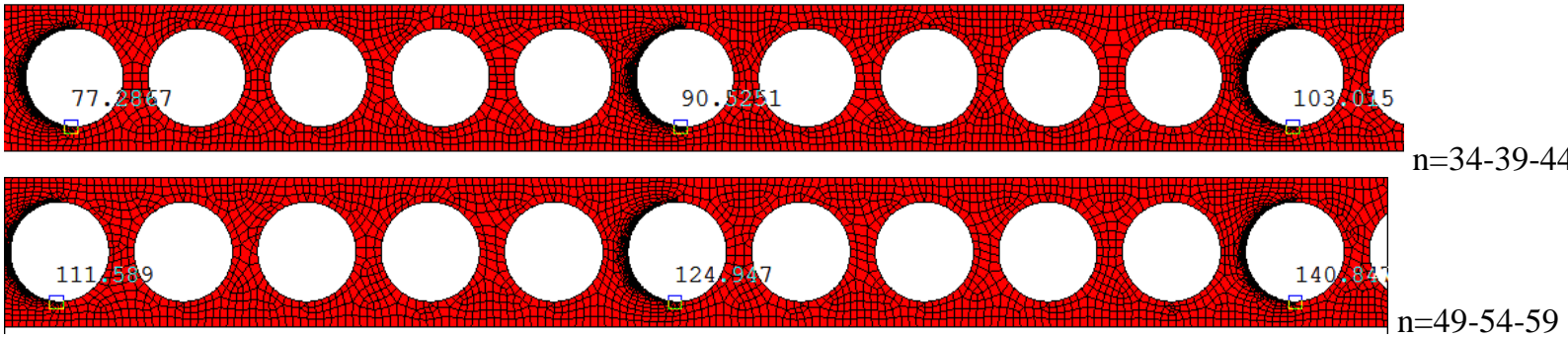

b

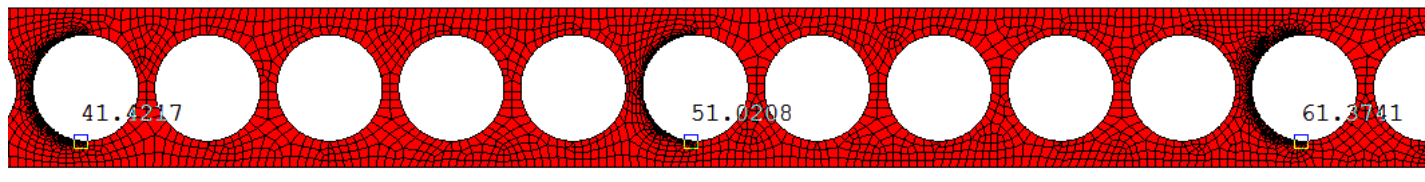

$n=19-24-29$

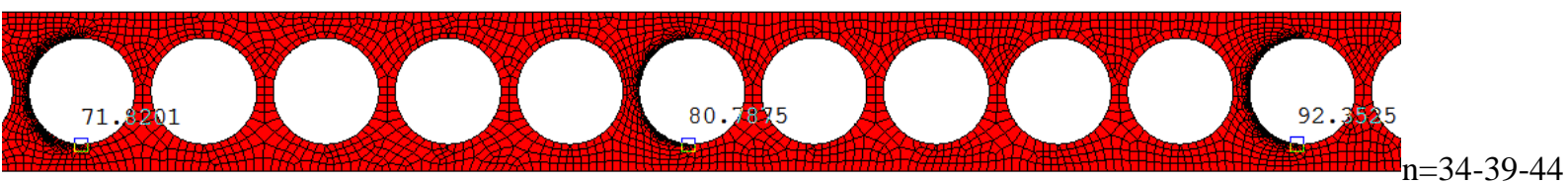

c

Fig. 4 Equivalent stresses in beam $4000-40-0.3-10-0.3 \mathrm{~cm}-0.667-\xi$ with different parameter $\xi$ : a) $\xi=0.5$; b) $\xi=0.25$; c) $\xi=0.15$ under $V=1 \mathrm{kN}$

Comparison of obtained by FEM results with values of equivalent stresses, calculated by Eq. (9) is represented in Table1. In this table in row "Parameters" are indicated relative width of web-posts of calculated beam and values of coefficients of force $\alpha_{V}$ and moment $\alpha_{M}$, under which magnitudes of equivalent stresses $\sigma_{\max }^{e q v}$ were calculated by Eq. (9). In the ended right column of Table 1 the total number of openings in considered beam is indicated. For constant length of beam the value $N$ will be different because of different width of web-posts.

For convenience of analysis the numerical data obtained by FEM near the contours of openings were joined in Table 1 , in which values of stresses $\sigma_{\max }^{e q v}$, calculated by Eq. (9) are also shown. 
Table 1

Stresses (MPa) in simply supported beam $4000-40-0.3-10-0.3 \mathrm{~cm}-0.667-\xi$ under action of shear force $V=1 \mathrm{kN}$

\begin{tabular}{|c|c|c|c|c|c|c|c|}
\hline $\begin{array}{c}\text { Number of opening, where } \\
\text { stresses are measured }\end{array}$ & 4 & 9 & 14 & 19 & 24 & 29 & $\begin{array}{l}\text { Total number } \\
\text { of openings }\end{array}$ \\
\hline Parameters & \multicolumn{7}{|c|}{$\alpha_{V}=5.61 ; \alpha_{M}=8.61 ; \xi=0.5$} \\
\hline Stresses on FEM $\sigma_{\max }^{e q v}$ & 14.7 & 27.8 & 41.9 & 56.8 & 70.4 & 85.1 & \multirow{3}{*}{$\mathrm{N}=100$} \\
\hline Stresses $\sigma_{\max }^{\text {eqv }}$ on Eq. (9) & 13.1 & 27.5 & 41.8 & 56.2 & 70.5 & 84.9 & \\
\hline Divergence in $\%$ & 10.9 & 1.1 & 0.2 & 1.1 & 0.2 & 0.2 & \\
\hline Number of opening & 34 & 39 & 44 & 49 & 54 & 59 & \\
\hline Parameters & \multicolumn{7}{|c|}{$\alpha_{V}=5.04 ; \alpha_{M}=8.24 ; \xi=0.25$} \\
\hline Stresses on FEM $\sigma_{\max }^{e q v}$ & 77.3 & 90.5 & 103.0 & 111.6 & 124.9 & 140.8 & \multirow{3}{*}{$\mathrm{N}=118$} \\
\hline Stresses $\sigma_{\max }^{e q v}$ on Eq. (9) & 79.8 & 91.2 & 102.7 & 114.1 & 125.6 & 137 & \\
\hline Divergence in $\%$ & 3.2 & 0.8 & 0.3 & 2.2 & 0.6 & 2.7 & \\
\hline Number of opening & 19 & 24 & 29 & 34 & 39 & 44 & \\
\hline Parameters & \multicolumn{7}{|c|}{$\alpha_{V}=6.48 ; \alpha_{M}=7.63 ; \xi=0.15$} \\
\hline Stresses on FEM $\sigma_{\max }^{e q v}$ & 41.4 & 51.0 & 61.4 & 71.8 & 80.8 & 92.4 & \multirow{3}{*}{$\mathrm{N}=130$} \\
\hline Stresses $\sigma_{\max }^{e q v}$ on Eq. (9) & 40.5 & 50.3 & 60.1 & 69.8 & 79.6 & 89.3 & \\
\hline Divergence in $\%$ & 2.2 & 1.4 & 2.1 & 2.8 & 1.5 & 3.4 & \\
\hline
\end{tabular}

Analysis of obtained by FEM data show that for beam with $\xi=0.5$ magnitudes of $\sigma_{\max }^{\text {eqv }}$ can be approximated with Eq. (9) under values of coefficient of force $\alpha_{V}=5.61$ and coefficient of moment $\alpha_{M}=8.61$.
For example, near $14^{\text {th }}$ opening of beam with $t_{w}=3 \mathrm{~mm}$ according to Fig. 4, $a$ the stresses calculated by FEM are equal to $41.9 \mathrm{MPa}$, and obtained on Eq. (9) have value:

$$
\sigma_{\max }^{e q v}=\left(5.61+8.61 \frac{(14-1)(1+0.5) 0.667}{6 \cdot 100 \cdot 3 /(400 \cdot 3)+1}\right) \frac{1 \cdot 10^{3}}{400 \cdot 3}=42.0 \mathrm{MPa}
$$

Divergence in values $\sigma_{\max }^{e q v}$, calculated by Eq. (10) and by FEM (Fig. 4,a), is $0.2 \%$, and for $29^{\text {th }}$ opening it will be on Eq. (9) $\sigma_{\max }^{e q v}=84.9 \mathrm{MPa}$ and by FEM $85.1 \mathrm{MPa}$ (Fig. 4, a). Divergence is not changed.

For beam with $\xi=0.25$ values of coefficients
$\alpha_{V}$ and $\alpha_{M}$ will be another ones. The magnitude of coefficient of force $\alpha_{V}$ will be equal 5.04 and coefficient of moment $\alpha_{M}=8.24$. Then for 59th opening calculation by FEM give $\sigma_{\max }^{e q v}=140.8 \mathrm{MPa}$ (Fig. 4, $b$ ) and by Eq. (9) result is represented below:

$$
\sigma_{\max }^{e q v}=\left(5.04+8.24 \frac{(59-1)(1+0.25) 0.667}{6 \cdot 100 \cdot 3 /(400 \cdot 3)+1}\right) \frac{1 \cdot 10^{3}}{400 \cdot 3}=137 \mathrm{MPa}
$$

In this case divergence is $2.7 \%$. For some other variants error of approximation with Eq. (9) can be bigger, but in average it describes quite well the stress state of cellular beams with circular openings.

Now it will be considered diapason of application of obtained Eq. (9). In Fig. 5 it is shown results of calculation of stresses of the same beam, that in Fig. 4, a but for openings with numbers $n=1-8$. Divergence in results obtained by FEM and by Eq. (9), near the 6th opening is $2.1 \%$, near the 7 th is $0.9 \%$, and near the $8^{\text {th }}$ is only $0.4 \%$. But for the 4th opening the difference is exceeding already
$10.9 \%$ (Table 1) and for openings 1-2-3 the divergence is still bigger.

Such big difference in values of stresses is connected with increasing role of shear force near the support because near the first opening influence of shear force is dominant due to small value of flexure moment which is near zero. From here it can be concluded (Fig. 6) the obtained Eq. (9) for value of $\sigma_{\text {max }}^{e q v}$ with indicated above coefficients $\alpha_{V}$ and $\alpha_{M}$ is applicable (give error not more the $3 \%$ ) only for openings with numbers $n \geq 6$. 


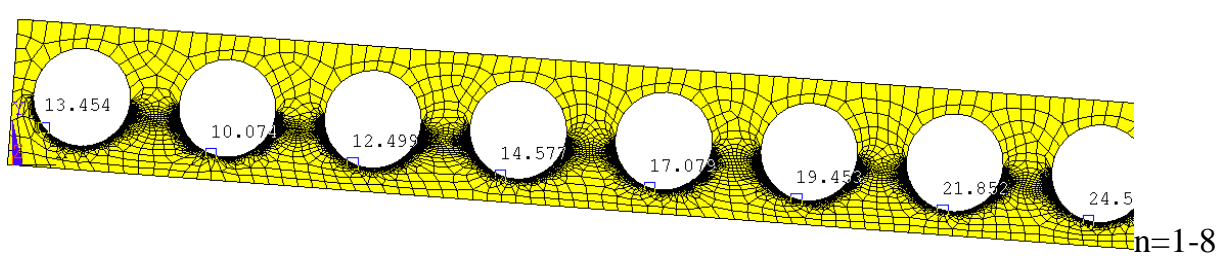

Fig. 5 Equivalent stresses in beam $4000-40-0.3-10-0.3 \mathrm{~cm}-0.667-0.5$ under $V=1 \mathrm{kN}$

As it can be seen from Fig.6, distribution of stresses $\sigma_{\max }^{e q v}$ along the beam length has lineal law, i. e. equivalent stresses, as and stresses in shelves are proportional to value of flexure moment so as shear force remains constant. Both lines determined by FEM and by Eq. (9) are practically coincide for beam with $t_{w}=0.3 \mathrm{~cm}$ in range of length with numbers of openings $n \geq 6$.

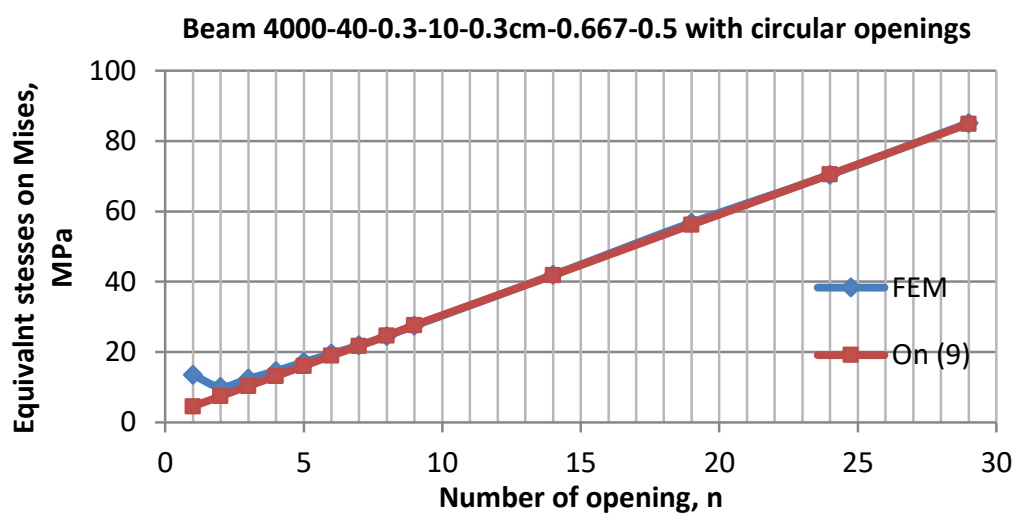

Fig. 6 Stress distribution of $\sigma_{\max }^{e q v}$, according to FEM and Eq. (9)

It is need to note the influence of shear force on value of equivalent stresses is not big, so far as maximum shear stresses from $V$ appear near the neutral axis of beam, and maximum normal stresses from moment $M$ take place in low part of openings. Only in vicinity of ended openings where flexure moment is small equivalent stresses $\sigma_{\max }^{\text {eqv }}$ reach essential value because of the shear force action
(Fig. 5).

Similar calculations performed for beams of the same dimensions and parameters of perforation that in previous case but with thickness of web $t_{w}=0.2 \mathrm{~cm}$ show the Eq. (9) gives rather good results in this case also. In Fig. 7 stress distribution for three variants of relative webposts $\xi=0.5, \xi=0.25$ and $\xi=0.15$ is represented.

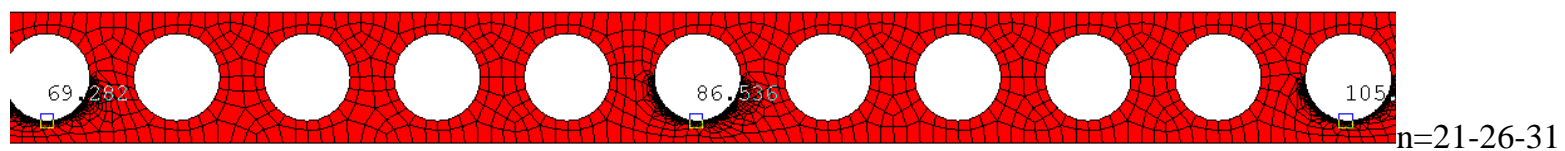

a

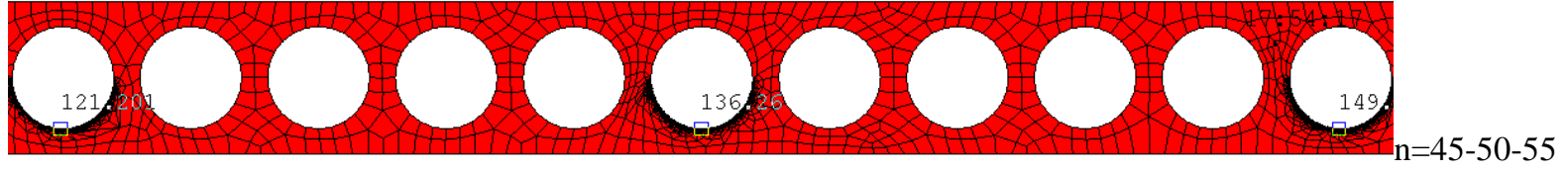

$\mathrm{b}$

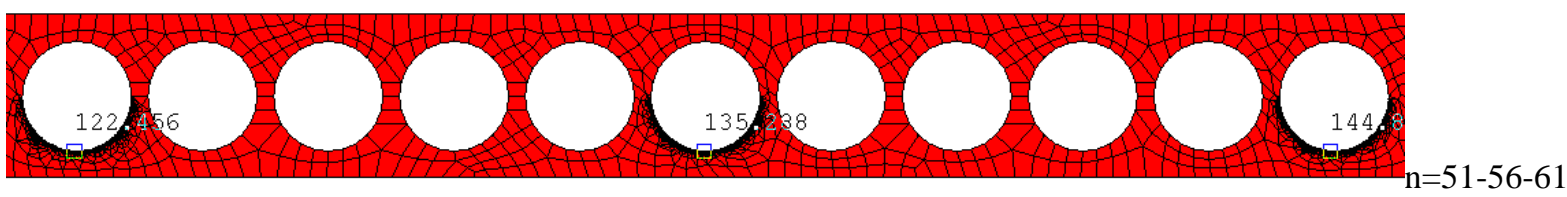

c

Fig. 7 Equivalent stresses in beams $4000-40-0.2-10-0.3 \mathrm{~cm}-0.667-\xi$ under $V=1 \mathrm{kN}$ in zones of openings : a) $\xi=0.5$; b) $\xi=0.25$; c) $\xi=0.15$

Results of calculation of equivalent stresses $\sigma_{\max }^{\text {eqv }}$ performed by FEM and by Eq. (9) are shown in Table 2. As it can be seen from Table 2, adopted earlier values of coefficients $\alpha_{V}$ and $\alpha_{M}$ give good results with Eq. (9) in this case also. In this distance divergence between data calculated by Eq. (9) and by FEM does not exceed 5.3\%. Comparison of stress level for different values $\xi$ allows to note tendency of reducing equivalent stresses on Mises with reducing of web-posts width. 
Table 2

Stresses (MPa) in simply supported beam $4000-40-0.2-10-0.3 \mathrm{~cm}-0.667-\xi$ under action of concentrated force $P=2 \mathrm{kN}$, applied in mid-span

\begin{tabular}{|c|c|c|c|c|c|c|c|}
\hline $\begin{array}{c}\text { Number of opening, where } \\
\text { stresses are measured }\end{array}$ & 21 & 26 & 31 & 36 & 41 & 46 & $\begin{array}{c}\text { Total number } \\
\text { of openings }\end{array}$ \\
\hline Parameters & \multicolumn{7}{|c|}{$\alpha_{V}=5.61 ; \alpha_{M}=8.61 ; \xi=0.5$} \\
\hline Stresses on FEM $\sigma_{\max }^{e q v}$ & 69.3 & 86.5 & 105.3 & 121.2 & 139.5 & 156.6 & \multirow{3}{*}{$\mathrm{N}=100$} \\
\hline Stresses $\sigma_{\max }^{e q v}$ on Eq. (9) & 73.0 & 89.6 & 106.2 & 122.7 & 139.3 & 155.8 & \\
\hline Divergence in $\%$ & 5.3 & 3.6 & 0.8 & 1.2 & 0.2 & 0.5 & \\
\hline Number of opening & 30 & 35 & 40 & 45 & 50 & 55 & \\
\hline Parameters & \multicolumn{7}{|c|}{$\alpha_{V}=5.04 ; \alpha_{M}=8.24 ; \xi=0.25$} \\
\hline Stresses on FEM $\sigma_{\max }^{e q v}$ & 83.8 & 95.6 & 109.3 & 121.2 & 136.3 & 149.8 & \multirow{3}{*}{$\mathrm{N}=118$} \\
\hline Stresses $\sigma_{\max }^{e q v}$ on Eq. (9) & 82.9 & 96.1 & 109.3 & 122.6 & 135.8 & 149.0 & \\
\hline Divergence in $\%$ & 1.1 & 0.5 & 0.1 & 1.2 & 0.4 & 0.6 & \\
\hline Number of opening & 36 & 41 & 46 & 51 & 56 & 61 & \\
\hline Parameters & \multicolumn{7}{|c|}{$\alpha_{V}=6.48 ; \alpha_{M}=7.63 ; \xi=0.15$} \\
\hline Stresses on FEM $\sigma_{\max }^{e q v}$ & 85.6 & 97.8 & 110.9 & 122.4 & 135.3 & 144.8 & \multirow{3}{*}{$\mathrm{N}=130$} \\
\hline Stresses $\sigma_{\max }^{\text {eqv }}$ on Eq. (9) & 86.9 & 98.2 & 109.4 & 120.7 & 132.0 & 143.2 & \\
\hline Divergence in $\%$ & 1.5 & 0.4 & 1.4 & 1.4 & 2.4 & 1.1 & \\
\hline
\end{tabular}

\section{Stress concentration factor under pure bending}

Consider now level of stresses under pure bending. Deformation of pure bending in central part of beam can be produced by loading of simply supported beam with two symmetrically applied concentrated forces. Research now influence on stress distribution of parameters of the web thickness and width of web-posts. Then for beams $4000-40-t_{w}-10-0.3 \mathrm{~cm}-0.667-0.5$ with different thickness of web it is possible to get pictures of stress distribution, represented in Fig. 8, from which it can be seen that under pure bending all stresses remain constant as in shelves so and near the contour of openings.

Level of stresses with reducing of the web thickness is growing because of lesser modulus of section.

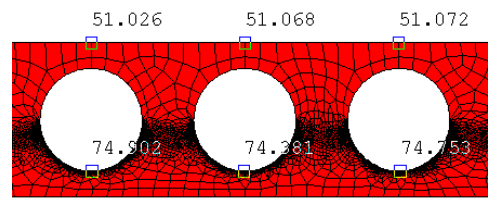

$\mathrm{a}$

\subsection{7}

58.731

58.658

58.674

58.725

58.728

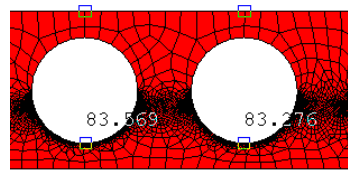

68.878

68.968

$\mathrm{b}$ 68.9 68.899

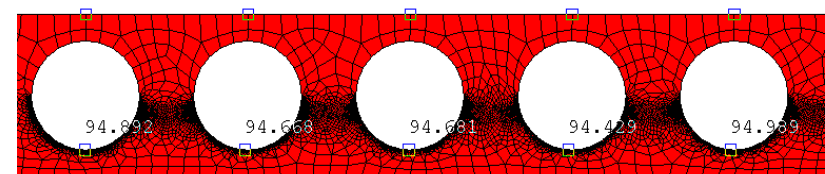

c

Fig. 8 Equivalent stresses in beam $4000-40-t_{w}-10-0.3 \mathrm{~cm}-0.667-0.5$ with different thickness of web:

a) $t_{w}=3 \mathrm{~mm}$; b) $t_{w}=2 \mathrm{~mm}$; c) $t_{w}=1 \mathrm{~mm}$

Under thickness of web $t_{w}=3 \mathrm{~mm}$ (Fig. 8, $a$ ) according to Eq. (2) the stress concentration factor will be equal to $\alpha_{\sigma}=74.9 / 51.1=1.47$, but with reducing thickness up to $t_{w}=2 \mathrm{~mm}$ (Fig. $8, b$ ) value of SCF become a little less $\alpha_{\sigma}=83.7 / 58.7=1.43$. For case of thickness $t_{w}=1 \mathrm{~mm}$ (Fig. 8, c) value of SCF became equal to $\alpha_{\sigma}=94.9 / 68.9=1.38$. Obtained results allow making conclusion that under pure bending the SCF is proportional to the web thickness.

Evaluate now influence of the web-posts width on the stress concentration under pure bending. Determine

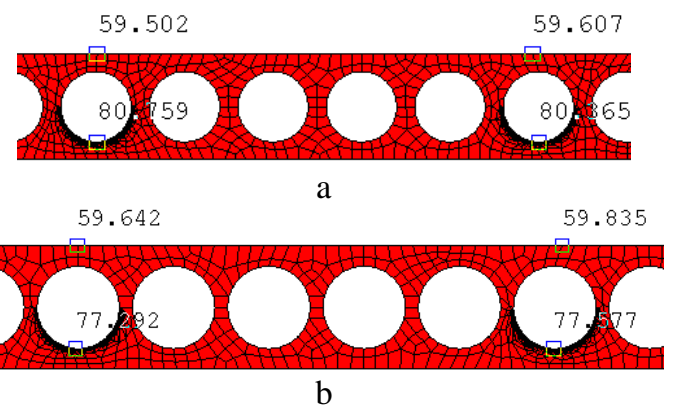

Fig. 9 Stresses $\sigma_{\max }^{e q v}$ in beam $4000-40-0.2-10-0.3 \mathrm{~cm}$

- $0.667-\xi$ under pure bending: a) $\xi=0.25$; b) $\xi=0.15$ 
now value of SCF for beam with dimensions $4000-40-$ $0.2-10-0.3 \mathrm{~cm}-0.667-\xi$ under $\xi=0.25$ and $\xi=0.15$ (Fig. 9, $a$ and $b$ respectively).

As it follow from Fig. 9, a reducing of relative width of web-posts from $\xi=0.5$ to $\xi=0.25$ lead to reducing of SCF from 1.47 to value $\alpha_{\sigma}=80.8 / 59.5=1.36$. The decreasing of SCF is about $7.5 \%$. For beam with $\xi=0.15$ value of SCF is $\alpha_{\sigma}=77.3 / 59.6=1.3$.

From here it can be concluded that in cellular beams with circular openings under pure bending SCF is almost proportional to relative width of web-posts.

\section{Conclusions}

1. It was obtained empirical Eq. (9) for evaluation of equivalent stresses $\sigma_{\text {max }}^{\text {eqv }}$ on Mises in beams with circular openings under joint action of shear force $V=$ Const and bending moment $M=V x$, changing on lineal law.

2. Eq. (9) was verified for variants with different web thickness an different relative width of web-posts in range $0.15 \leq \xi \leq 0.5$ under relative height of openings $\beta=0.667$.

3. Magnitude of stress concentration factor does not exceed $\alpha_{\sigma} \approx 1.5$ under pure bending for beam with $\beta=0.667$.

\section{References}

1. Handbook on structural mechanics of ship. v.2. 1982Leningrad: Shipbuilding. 464p. (in Russian).

2. Vesraghavachary, K. 1972.Stress distribution in castellated beam, Proc of ASCE, Struct Div. 95(2): 7882.

3. Cheng, W.K.; Hosain, M.U.; Neis, V.V. 1972. Analysis of castellated steel beams by the finite elements method, Proc of Special Conf on FEM in Civil Eng, Moutrede, Canada: 58-64.

4. Liu, T.C.H.; Chung, K.F. 2003. Steel beam with large web openings of various shapes and sizes: finite element investigation, J. Constr Steel Res 59(9): 11591176. http://dx.doi.org/10.1016/S0143-974X(03)00030-0.

5. Verissimo, G.S.; Fakury, R.H.; Ribero, J.C. 2003. Design aids for unreinforced web openings in steel and composite beams with W-shapes, Eng J. 20(3): 1-14.

6. Dionisio, M. at al. 2005. Determination of Critical Location for Service Load Bending Stresses in NonComposite Cellular Beams: Research Report 8. Villanova University.

7. Lagros, N. D. at al. 2008. Optimum design of steel structures with web opening, J of Eng Struct 30(4): 2528-2537.

8. Devinis, B.; Kvedaras A. K. 2008. Investigation of rational depth of castellated steel I-beam, J of Civil Eng. and Management. 149(3): 163-168.

9. Hoffman, R. at al. 2010. Analysis of stress distribution and failure behavior of cellular beams, Research Report 7. Villanova University.

10. Tsavdaridis, K. D. 2010. Failure modes of composite and non-composite perforated beams sections with var- ious shapes and sizes of web openings, $\mathrm{PhD}$ thesis. City University, London.

11. Chhapkhane, N.K.; Sashikant, R. K. 2012. Analysis of stress distribution in castellated beam using finite element method and experimental techniques, Int. J. of Mech Eng Appl Res 3(3):190-197.

12. Wakchaure, M.R.; Sagade, A.V. 2012. Finite element analysis of castellated steel beam. Int. J. of Eng. and Innovative Technology (IJEIT). 2(1): 365-372.

13. Wang, P.; Wang, X.; Ma, N. 2014. Vertical shear buckling capacity of web-posts in castellated steel beams with fillet corner hexagonal web openings. Engineering Structures. 75: 315-326.

14. Durif, S.; Bouchair, A.; Vassart, O. 2014. Experimental and numerical investigation on web-post member from cellular beams with sinusoidal openings. Eng. Struct. 59: 587-598.

15. Dobrachev,V.M.; Litvinov, E.V. 2003. Analytical determination of stress-strain state of web-post of perforated beam, Izvestia vuzov. Construction. 5: 128-133 (in Russian).

16. Pritykin, A. 2009. Stress concentration in beams with one row of hexagonal openings, Vestnik of Moscow State Struct. University. 1: 118-121 (in Russian).

\section{A. I. Pritykin, A.S. Lavrova}

\section{PREDICTION OF THE STRESS LEVEL AND STRESS CONCENTRATION IN CELLULAR BEAMS WITH CIRCULAR OPENINGS}

S u m m a r y

In the work on base of calculations by FEM of cellular I-beams with circular openings the approximate relation for evaluation of stress level in vicinity of openings under transverse bending was obtained. Calculation of simply supported cellular I-beams under action of one concentrated force applied in mid-span and two symmetrically applied forces was performed. Proposed relation for equivalent stresses on Mises near openings was applied for beams with different thickness of web and different relative width of web-posts. Relative height of openings in all cases was equal to 0.667 . It was also calculated stress concentration factor for case of pure bending.

Key words: cellular I-beam, circular openings, von Mises stress, stress concentration factor, FEM.

Received June 03, 2016 Accepted August 04, 2017 